\title{
Avaliação do uso de blend de levedura em rações para suínos de fase de creche, crescimento e terminação
}

\author{
Evaluation of use of yeast blends in diets for nursey, growth and finishing pigs \\ Evaluación del uso de mesclas de levaduras em dietas para cerdos de guardería, crecimiento y \\ finalización
}

\section{Resumo}

Diante dos desafios encontrados atualmente na produção de suínos, o uso de aditivos tornou-se uma das principais estratégias nutricionais que auxiliam na diminuição do uso de antibiótico nas dietas de suínos. Um dos principais aditivos utilizados na nutrição de suínos são as leveduras, que têm em sua composição produtos que podem atuar como prebióticos e probióticos. Com isto, objetivou-se realizar uma revisão de literatura sobre o uso de leveduras na dieta de suínos nas fases de creche, crescimento e terminação. As variabilidades de estudos demonstram resultados diferentes em todas as fases de produção, pois fatores como o tipo de levedura utilizada, o ambiente que os animais estão submetidos e a variabilidade de espécies e microrganismos dos aditivos podem impactar nos resultados esperados, também o tipo de processamento que a levedura é submetida pode influenciar no seu mecanismo de ação, o que pode ter impacto na eficiência da mesma. Estudos demonstram que as leveduras e seus produtos melhoram a saúde intestinal por modular a microbiota, aumentando o tamanho das vilosidades e profundidade das criptas intestinais, reduzindo também as bactérias patogênicas. Com isso é possível concluir através da revisão realizada, que há necessidade de mais estudos que possam demonstrar a eficiência do uso das leveduras na saúde intestinal dos animais e desempenho zootécnico.

Palavra-chaves: Aditivos; Desempenho; Prebióticos; Probióticos; Saúde intestinal.

\section{Abstract}

In view of the challenges currently encountered in pig production, the use of additives has become one of the main nutritional strategies that help to reduce the use of antibiotics in pig diets. One of the main additives used in swine 
nutrition is yeast, which has products in its composition that can act as prebiotics and probiotics. With this, the objective was to carry out a literature review on the use of yeast in the diet of swine in the nursery, growth and termination phases. The variability of studies shows different results in all stages of production, since factors such as the type of yeast used, the environment that the animals are subjected to and the variability of species and microorganisms of the additives can impact on the expected results, also the type of processing that yeast is subjected can influence its mechanism of action, which can have na impact on its efficiency. Studies show that yeasts and their products improve intestinal health by modulating the microbiota, increasing the size of villi and depth of intestinal crypts, while also reducing pathogenic bacteria. Thus, it is possible to conclude through the review, that there is a need for more studies that can demonstrate the efficiency of the use of yeasts in the intestinal health of animals and zootechnical performance.

Keywords: Additives; Performance; Prebiotics; Probiotics; Intestinal healthy.

\section{Resumen}

Ante los retos que afronta actualmente la producción porcina, el uso de aditivos se ha convertido en una de las principales estrategias nutricionales que ayudan a reducir el uso de antibióticos en la dieta porcina. Uno de los principales aditivos utilizados en la nutrición porcina es la levadura, que tiene en su composición productos que pueden como prebióticos y probióticos. Con esto, el objetivo fue realizar una revisión de la literatura sobre el uso de levaduras en la dieta de los porcinos en las fases de crianza, crecimiento y terminación. La variabilidad de los estudios muestra resultados diferentes en todas las etapas de producción, ya que factores como el tipo de levadura utilizada, el ambiente al que están sometidos los animales y la variabilidad de especies y microorganismos de los aditivos pueden incidir en los resultados esperados, también el tipo de procesamiento al que se somete la levadura puede influir en su mecanismo de acción, lo que puede repercutir negativamente en su eficacia. Los estudios demuestran que las levaduras y sus productos mejoran la salud intestinal al modular la microbiota, aumentando el tamaño de las vellosidades y la profundidad de las criptas intestinales, al tiempo que reducen las bacterias patógenas. Así, es posible concluir a través de la revisión, que se necesitan más estudios que puedan demostrar la eficiencia del uso de levaduras en la salud intestinal de los animales y el desempeño zootécnico.

Palabras-clave: Aditivos; Rendimiento; Prebióticos; Probióticos; Salud Intestinal.

\section{Introdução}

A suinocultura brasileira tem se intensificado para atender a demanda do mercado consumidor interno e externo, pelo fato de ser uma das carnes mais consumidas globalmente e possuir um mercado cada vez mais exigente. Desta forma a suinocultura brasileira se destaca como atividade viável para produção de proteína animal de qualidade e altamente rentável, entretanto devemos nos atentar a um dos principais fatores que influenciam na produção e na busca por mais eficiência na suinocultura, a nutrição (Lima et al., 2020).

Visando a diminuição do uso de antibióticos na produção de suínos, devido aos riscos à saúde humana, alguns países proibiram a utilização dos mesmos como promotores de crescimento, tornando assim necessária a utilização de substitutos como as leveduras, que além de possuir boas características nutricionais, também possuem ação antibactericida, impedindo o estabelecimento de bactérias patogênicas no intestino dos animais melhorando a integridade intestinal, passando dessa forma a fazer parte da lista de opções de ingredientes das dietas dos animais de produção (Barba-Vidal et al., 2019 \& Lima et al., 2020).

O uso de aditivos na suinocultura se tornou uma das tecnologias nutricionais mais utilizadas nos últimos anos, buscando resultados em conversão alimentar, eficiência alimentar e ganho de peso dos animais. A diminuição do tempo da maturação fisiológica dos animais é buscada pelos produtores de suíno, para que os animais que saiam da maternidade apresentem um desempenho satisfatório nas próximas fases, com melhor qualidade de microvilosidades e com uma microbiota intestinal com maior colonização de microrganismos benéficos (Silva et al., 2014).

Com o intuito de aumentar a capacidade de utilização dos nutrientes disponíveis na dieta e promover uma melhor saúde intestinal nos animais, o uso de aditivos, como as leveduras tem sido proposto por pesquisadores a fim de proporcionar melhor desempenho e desenvolvimento aos animais (Santos et al., 2016). Sendo assim, esta revisão tem como objetivo apresentar os efeitos de leveduras ou blends de leveduras em rações para suínos de diferentes fases de criação sobre o seu desempenho zootécnico. 


\section{Metodologia}

Para realização da revisão de literatura do presente estudo foi utilizada a abordagem exploratória, com pressupostos da pesquisa bibliográfica e documental, segundo a metodologia proposta por Pereira et al., (2018), tendo como produto uma revisão de literatura, compilando informações científicas relacionadas à temática da utilização de leveduras na dieta de leitões na fase de creche, crescimento e terminação. Fez-se seleção de artigos utilizando as seguintes bases: Scielo, Google Acadêmico, Science Direct e PubMed. Utilizando para busca as palavras chaves: aditivos, desempenho, leveduras, prebióticos, probióticos, saúde intestinal. Posteriormente, realizou-se seleção de artigos, onde o período utilizado para escolha das pesquisas foi o mais recente possível (2011 - 2021).

\section{Revisão de Literatura}

\subsection{Fisiologia Suína Pós-Desmame}

Atualmente, o desmame dos leitões no Brasil é realizado dos 21 aos 28 dias de vida dos leitões, sendo necessário uma série de medidas nutricionais e de manejo, para que não haja interferência no desempenho dos animais, provocado pela mudança da dieta dos animais. Com isso torna-se notória a necessidade de se entender a fisiologia digestiva dos animais, buscando assim, atender as exigências dos mesmos a fim de manter a integridade fisiológica dos animais (Almeida et al., 2017).

Após o desmame, um dos fatores a ser levado em consideração é a mudança na dieta dos animais, os quais se alimentavam de um alimento líquido altamente digestível que é o leite e logo após passam por uma mudança na dieta, onde passam a ingerir alimentos mais sólidos, com maior utilização de produtos de origem vegetal que possuem menor digestibilidade, havendo ainda presença de fatores anti-nutricionais, os quais impactam negativamente na absorção dos nutrientes, como é o caso da soja que é a principal fonte proteica utilizada na dieta de suínos (Garcia et al., 2018 \& Karasova et al., 2021).

Ao serem desmamados, os leitões passam a receber alimentos sólidos na dieta, fazendo com que haja baixo consumo dos animais nos primeiros dias. Tendo isso em mente, torna-se interessante a realização de fornecimento gradual de dietas sólidas ainda no período de lactação dos leitões, assim promovendo uma adaptação dos animais, fazendo com que esses não sofram impactos negativos devido à mudança brusca de alimento na transição para a fase de creche (Chamone et al., 2010).

Alguns autores citam que a fase de desmame é uma fase de transição de imunidades, a mesma se tornando ativa após a separação dos leitões da fêmea suína. Porém os leitões ainda não apresentam uma capacidade fisiológica efetiva, visto que há uma baixa produção de enzimas endógenas, bicarbonato e muco, os quais atuam na digestão e absorção dos nutrientes (Malheiros, 2018). Para o mesmo autor quando há uma digestão incompleta do alimento não há a ativação da secreção endócrina da secretina e colecistoquinina, o que atua negativamente na secreção exócrina do pâncreas, de tripsina, amilase e lipase.

Algumas bactérias patógenas são capazes de secretar enterotoxinas como por exemplo a Escherichia coli e Salmonella spp. as quais provocam diarreias e outros distúrbios fisiológicos nos animais (Galvez et al., 2020 \& Silva et al., 2020). Por isso o HCL é importante nessa situação, visto que uma das suas funções é a eliminação de patógenos, promovendo a diminuição das infecções entéricas. Entretanto, leitões recém desmamados apresentam uma baixa produção do HCL e um pH mais elevado quando equiparados aos animais adultos, o que ajuda a justificar os problemas de desordens intestinais ocasionados pela maior ineficiência em manter o pH gástrico mais ácido (Rostagno \& Pupa, 2018).

O intestino delgado dos animais é local onde situam-se as vilosidades, as quais atuam na absorção dos nutrientes. (Dong et al., 2020) A morfologia e consequentemente a integridade desta mucosa dependerá dos nutrientes fornecidos aos 
animais, sendo que ao ocorrer o desmame e posteriormente mudança de dieta, há uma influência negativa dessa troca sob as vilosidades, interferindo na altura das mesmas e consequentemente na absorção dos nutrientes (Campbell et al., 2013).

Para diminuir o efeito provocado pelo desmame, as enzimas digestivas devem estar atuando de forma eficiente, promovendo então uma inclusão de enzimas exógenas nas dietas. Atualmente o uso dessas enzimas tem como objetivo aumentar a eficiência digestiva dos animais, neste caso, proporcionando um melhor aproveitamento dos nutrientes fornecidos pelos alimentos. Paralelamente a isso, emprega-se também a utilização de leveduras, com intuito de manter a saúde intestinal dos animais, diminuindo os efeitos negativos provocados por microrganismos patógenos (Luna et al., 2015; Zhang et al., 2019).

Quando os leitões nascem, os mesmos apresentam um déficit em algumas enzimas, como por exemplo as enzimas maltase, sacarase, protease e a amilase (Wang et al., 2020). Isso ocorre devido as dietas na fase lactente na maioria das granjas serem apenas o leite materno, o que as tornam pouco eficiente. Ao contrário da lactase que apresenta alta atividade nesta fase, mas decresce com o passar da idade dos animais e o fornecimento de alimentação sólida. Além da adaptação que deve ser feita com as enzimas, os animais necessitam de adequação do pH e a motilidade intestinal.

\subsection{Impacto do Desmame em Leitões}

A suinocultura é composta por uma cadeia produtiva, onde apresenta algumas etapas de produção, desde a inseminação das fêmeas até os animais terminados. Entretanto, dentre essas etapas uma chama bastante atenção no âmbito de produção suinícola, trata-se a fase de desmame. Pois, essa etapa é crucial no que diz a respeito da melhora do desempenho produtivo dos leitões nas fases subsequentes (Almeida et al., 2017 \& Lopes et al., 2020).

O desmame é tido como uma das etapas mais importantes da cadeia produtiva de suínos, pelo fato do mesmo estar relacionado com a separação do leitão da mãe, expondo os animais a um novo tipo de ambiente, ocasionando uma exposição a desafios como, disputa por alimento e convivência com outros animais de leitegadas distintas. Torna-se necessário adotar estratégias nutricionais como o uso de rações pré-iniciais, as quais apresentam melhor palatabilidade e digestibilidade (Almeida et al., 2017 \& Vicari Junior et al., 2020).

Tendo isso em mente, torna-se evidente a necessidade de se atentar para os impactos da etapa do desmame na produtividade dos animais, visto que Patil et al., (2015), relatam que o desmame pode interferir negativamente na vida dos leitões, pois, aumenta a exposição frente a desafios que geram impactos como, redução de ingestão de alimento, aumento da incidência de diarreia, redução de peso corporal e por último não menos importante, danos causados ao intestino dos animais.

Outro fator que chama atenção no processo de desmame é a idade em que o mesmo será realizado. Atualmente as granjas vêm adotando a utilização do desmame entre 21 e 28 dias, considerado desmame precoce quando comparado ao desmame natural, onde os animais ainda estão fisiologicamente imaturos, necessitando de estratégias de manejo e nutricionais para minimizar os impactos negativos que podem ser provocados pela baixa eficiência de digestão dos nutrientes (Silva et al., 2012).

Pensando nisso, em estudo realizado por Araújo et al. (2011), os autores citam que animais desmamados precocemente (21-28 dias), estão mais propensos a apresentarem comportamentos indesejáveis, como, canibalismo, menor tempo frente ao comedouro dentre outros, quando comparados a animais desmamados em mais tempo de vida (35 dias), evidenciando assim a necessidade de entender e realizar tal procedimento de maneira adequada, seguindo instruções de manejo além de respeitar capacidades físicas e fisiológicas dos animais.

Ocorrência de doenças entéricas figura entre os impactos negativos gerados pelo desmame, pois estas interferem na saúde intestinal dos animais, reduzindo o consumo de alimentos e a toda capacidade de aproveitamento de nutrientes, e como consequência disso há uma redução do desempenho dos leitões (Almeida et al., 2017). 
Pluske et al., (2018), citam que a saúde intestinal está relacionada com uma série de fatores, e deve-se buscar com o uso de aditivos, microrganismos benéficos que favoreçam a microbiota intestinal dos animais, permitindo que os mesmos consigam um melhor desempenho frente aos desafios da fase de desmame. Tendo isso em mente faz-se necessário a inclusão de probióticos nas dietas dos animais, como é o caso das leveduras, pois estas possuem capacidade de modular o microbioma intestinal, favorecendo o crescimento de bactérias benéficas e consequentemente reduzindo a colonização dos patógenos intestinais (Xiong et al., 2015 \& Wang et al., 2020).

\subsection{Influência dos Aditivos na Saúde Intestinal dos Suínos}

Com a intensificação dos sistemas de produção o uso de antibióticos como fonte promotora de crescimento se fez necessário durante alguns anos na produção de animais monogástricos, com a justificativa de que o uso dos agentes antimicrobianos seria fornecido aos animais em níveis subterapêuticos para melhorias no desempenho e eficiência alimentar (Bezerra et al., 2017 \& Lima et al., 2020).

Com isso nos últimos anos a preocupação com o uso de antibióticos fez com que alguns países como a União europeia proibissem o uso de antibióticos em animais de produção, o que provocou uma mudança nos desafios sanitários, manejo e estratégia nutricional dos animais. Devido à intensidade de produção e genética dos animais, os mesmos necessitam de alternativas que possam substituir os antibióticos com menor ou sem nenhum resíduo no produto final (Liu et al., 2018).

Sendo assim um dos principais assuntos estudados atualmente é a saúde intestinal dos animais, a qual visa o aumento de microrganismos benéficos e a diminuição de patógenos que podem provocar a colonização do trato gastrointestinal dos animais (Almeida et al., 2017). O desafio de se utilizar aditivos é ir além de ambientes experimentais, os quais apresentam ambiente controlado em temperatura, umidade e número de animais por baias. Com isso empresas buscam atender a demanda de granjas de criação intensiva com produtos que possam sustentar o desafio que os animais estão submetidos.

Silva et al., (2020) define a saúde intestinal como o equilíbrio existente entre a mucosa intestinal e o conteúdo luminal no intestino, o qual deve apresentar características estruturais e funcionais de forma eficiente, estando preservadas ou mantidas de acordo com a fase de produção do animal. Lesões nos enterócitos e a quantidade de microrganismos patógenos presentes no meio intestinal, influenciam na capacidade de digestão dos alimentos fornecidos e na absorção dos nutrientes (Gazoni, 2012).

Os animais que estão fisiologicamente imaturos, como suínos na fase de creche passam por maiores desafios no período que é realizado o desmame, um dos principais fatores que influenciam é a mudança de dieta, podendo causar severas lesões nas microvilosidades, afetando a capacidade absortiva dos enterócitos (Zhong et al., 2019). Havendo presença de novos substratos no trato gastrointestinal, os quais precisam passar por um processo de digestão e absorção, faz com que haja o desiquilíbrio intestinal nas primeiras semanas pós-desmame, devido a sua baixa eficiência de liberação de Hcl e enzimas endógenas (Xu et al., 2017 \& Feitosa et al., 2020).

Alguns autores observaram que o uso de aditivos melhora a digestibilidade dos nutrientes, o desempenho dos animais, a capacidade antioxidativa e promove uma seleção benéfica de microrganismos (Zeng et al., 2015; Zeng et al.,2014).

Os probióticos são microrganismos benéficos que agem por competição aos microrganismos patogênicos no intestino do hospedeiro, ligando a células intestinais e impedindo assim a aderência e multiplicação de bactérias indesejáveis. Outros efeitos são encontrados com o uso de probióticos, onde se observa uma melhor normalização e recuperação da permeabilidade dos enterócitos. Essa recuperação se deve ao efeito que as bactérias causam nas células intestinais, regulando assim o sistema imune, balanceando secreções pró e anti-inflamatórias, além de reduzir a hipersensibilidade (Lima et al., 2020).

Por conseguinte, sua principal aplicabilidade é para controle de infecções gastrintestinais com intuito de prevenção e abolição de tratamentos. Os probióticos não eliminam as bactérias como a maioria dos antimicrobianos a base de antibióticos, 
mas são capazes de modular o ambiente da qual são estabelecidos, reduzindo os riscos de doenças entéricas intestinais em harmonia com o sistema imunológico do hospedeiro (Lima et al., 2020).

Existem diversos tipos de microrganismos utilizados como probióticos, com destaque são os dos gêneros Lactobacillus, Bifidobacterium, Enterococcus, Bacillus e leveduras (Zhang et al., 2020). Existem peculiaridades dos microrganismos para que esses possam vir a ser utilizados como probióticos, são: fazer parte da flora já existente no hospedeiro, ter alta capacidade de sobrevivência e colonização, ter boa capacidade de ligação ao epitélio intestinal, sobreviver à ação de enzimas digestivas do hospedeiro, não ser tóxicos ou patogênicos, ser cultivável em escala industrial, ser comerciável e estimular a capacidade imune do hospedeiro (Souza et al., 2020).

Santos et al., (2016), cita em seu trabalho que como aditivos essas bactérias são adicionadas a nutrição de suínos, promovendo uma competição por nutrientes, uma vez que bactérias patogênicas e benéficas disputam por nutrientes específicos de cada espécie, a fim de garantir a sua multiplicação e ordem no intestino do hospedeiro, garantido um ambiente saudável. O mesmo autor ainda cita que a inclusão de 200 a 300 ppm de probióticos em dietas de suínos em crescimento, diminui a incidência de diarreia em animais desmamados, além de melhorar o consumo e a digestibilidade da ração.

Os prebióticos também são aditivos, porém são ingredientes que não são digeridos pelas enzimas presentes no trato gastrointestinal dos animais, todavia, são fermentados pelas bactérias e gera substancias que estimulam o crescimento e atividade de bactérias benéficas para o hospedeiro, inibindo assim o crescimento e colonização de bactérias patogênicas (Assis et al., $2014 \&$ Sessin, 2018)

Brito et al., (2013), citam em sua revisão que o efeito do aditivo probiótico e prebiótico sobre desempenho de leitões desmamados aos 23 dias mostraram que essa adição proporcionou desempenho dos animais semelhantes quando comparado ao tratamento com antibióticos. O seu uso ainda melhorou a qualidade da carcaça, apresentando uma carne com menor perda de água durante o processo de cozimento, melhor retenção e firmeza da carne.

A ação principal dos prebióticos é através do estimulo, ativação e crescimento de um determinado grupo de bactérias benéfica. Sua atuação está relacionada aos probióticos, onde irá constituir sobre a alimentação das bactérias probióticas. Além disso os prebióticos atuam como forma de bloqueio nos sítios de aderência, reduzindo a capacidade das bactérias patogênicas de aderir a parede do intestino. Existem diversos tipos de aditivos prebióticos, porem as mais utilizadas na alimentação animal são os frutoligossacarídeos e mananoligossacarídeos (Lima et al.,2020).

Com o objetivo de estimular o desenvolvimento das Bifidobacterium e dos Lactobacillus, os prebióticos vêm ganhando destaque na nutrição animal, uma vez que esse vem possuem uma grande capacidade de produção de ácido láctico e acético. Com a formação desses ácidos, ocorre assim a diminuição do pH, onde irá favorecer também a atividade de enzimas digestivas e conter a população de microorganismos patogênicos (Sessin, 2018).

O Mananoligossacarídeos (MOS) possui sua origem da parede celular de leveduras Saccharomyces cerevisiae, da qual é usado como probióticos na nutrição animal. Atuando na modulação da flora intestinal, com o intuito de reduzir a taxa de renovação da mucosa, estimulando assim o sistema imune do animal, uma vez queira melhorar e proteger o a microbiota intestinal do animal, diminuindo lesões e propiciando maior altura das vilosidades e profundidade das criptas intestinais (Assis, et al., 2014).

Os prebióticos MOS são aptos a conservar a saúde do trato gastrointestinal, pois beneficia a proliferação e multiplicação de bactérias benéficas, além de funcionar como adsorvente de bactérias patogênicas, aumentando a resistência contra doenças entéricas, inibindo sua ligação no epitélio do intestino causando assim a sua eliminação. Esses efeitos irão melhorar a absorção de nutrientes presentes na ração melhorando o desempenho dos animais (Silva et al., 2020, Vargas, 2014).

Em revisão realizada por Halas e Nochta (2012), os autores buscaram relatar a função e modo de ação dos (MOS) na dieta de suínos, principalmente em dietas de leitões no pós-desmame. É relatado que este probiótico possui maior eficiência 
quando acrescentado em dieta de leitões expostos a ambientes desafiadores higienicamente, onde em situações como essa, o produto melhora a resistência dos leitões a doenças, principalmente entéricas além de promover melhor absorção de nutrientes e consequentemente melhora no desempenho dos animais.

Os frutooligossacarídeos (FOS) são prebióticos compostos por polímeros de frutose ligados a uma unidade de glicose de origem vegetal, também obtidos sinteticamente. Sua inclusão em dietas de não ruminantes resulta em alterações metabólicas do animal, levando uma melhoria na eficiência de aproveitamento dos nutrientes das dietas, reduzindo os quadros clínicos de diarreia (Silva et al., 2018; Kuhn et al., 2015).

Os FOS podem fazer com que os microrganismos benéficos os utilizem como nutrientes para o seu crescimento e multiplicação. Dessa forma eles servem principalmente como inibidores de microrganismos patogênicos, principalmente Salmonella e Escherichia coli, que por sua vez, são gram-negativos e são ineptos de fermentar os FOS, sofrendo redução no seu crescimento populacional quando em contato com esses carboidratos (Wang et al., 2019)

\subsection{Uso de Leveduras na fase de Creche}

As leveduras são microrganismos unicelulares, as quais são oriundas do processo de fermentação, sendo uma antiga fonte proteína consumida pelo homem e animais de produção. Apresentam em sua constituição membranas celulares bem definidas e resistentes. Suas constituições são variadas, prevalecendo hidratados de carbono, o que a tornou uma importante fonte de estudos para a nutrição animal (Garcia et al., 2019).

Com a tendência de proibição de uso de antibióticos como fonte de promotores de crescimento, as leveduras atuam como um dos substitutos para utilização nas dietas de leitões de creche (Robles et al., 2013). Berto (2017), cita que trabalhos utilizando levedura na nutrição de suínos vem sendo desenvolvidos desde os anos 80, onde tinham o desejo de substituir parcialmente ou totalmente a soja nas dietas dos animais. Com o desenvolver das pesquisas e os conhecimentos gerados durante as pesquisas levaram as empresas no desenvolvimento de novos produtos. Em meio a essas pesquisas desenvolveram a levedura hidrolisada cujo seus constituintes celulares podem ser mais bem aproveitados pelos animais.

Visto isso, os autores relatam que a inclusão de probióticos como é o caso de leveduras, são alternativas benéficas para reverterem os danos causados pelo desmame na suinocultura, pois estas podem estimular o desenvolvimento de uma microbiota saudável, o que por sua vez irá atuar na prevenção de patógenos do microbioma intestinal.

A inclusão de leveduras nas dietas animais proporciona alguns bons resultados como, melhora do equilíbrio da microflora no trato gastrointestinal (TGI), participa da maturação de tecidos no TGI, modula a resposta imune reduzindo consequentemente patógenos, reduz a diarreia pós-desmame e melhora a taxa de crescimento dos animais, conforme observado nos trabalhos estudados por Vohra et al., (2016).

Há uma intensificação na utilização de ingredientes contendo leveduras em dietas animais, isso se deve ao fato da proibição de utilização de antibióticos que atuam como promotores de crescimento, o que por sua vez aumenta a inclusão de leveduras nas dietas animais, principalmente em suínos, pois estas possuem capacidade de controlar a microbiota patogênica, contribuindo para um bom desempenho animal (Shurson, 2018 \& Gonzáles-Ortiz et al., 2020).

A composição da microbiota intestinal garante a capacidade de saúde da mesma em suínos, bem como um aumento na população de bactérias do gênero bifidobacterium, lactobacilos e eubactérias melhoram a saúde dos animais além de diminuir o risco de doenças.

Existem diversos tipos de aditivos no mercado usados na nutrição de suínos, porem as leveduras têm seu destaque, principalmente as espécies Sacchaaromyces cerevisiae, Kluyveromyces, Hansenula e Pichiae Candida, que tem grande valor na indústria e comércio. Muitas das vezes essas espécies são encontradas provindas da fermentação alcoólica, provindos das destilarias de cana de açúcar, ou obtidas através da produção de cerveja (Berto, 2017). 
A levedura Sacchaaromyces cerevisiae, é um subproduto da fermentação alcoólica, que pode ser obtido pelo processo de centrifugação, onde além de características nutricionais, esses são indicados como probióticos, impedindo o estabelecimento e adesão de microrganismos patogênicos no intestino. As leveduras dessa espécie possuem características em sua parede celular que impedem que bactérias patogênicas se acoplem à parede intestinal, pois fazem parte de sua constituição MOS fosforilados, caracterizados como moléculas não digestíveis, onde atuam como estimulo ao crescimento de bactérias benéficas (Sant'ana et al., 2017).

A inclusão de levedura seca (Saccharomyces cerevisiae) em quatro diferentes níveis (0, 5, 10 e $15 \%)$, foi objeto de estudos de Araújo et al., (2011). Os autores citam que a utilização pode ser utilizada a níveis de 15\% para suínos da fase inicial, justificando que os animais que receberam a ração contendo $15 \%$ de levedura desidratada apresentaram, numericamente, melhor ganho de peso e, quando receberam 5\%, melhor conversão alimentar. Os autores também avaliaram o efeito da levedura na morfologia intestinal e observaram que a altura das vilosidades e a profundidade das criptas não apresentou diferença quando utilizado os diferentes níveis de levedura na ração.

Os efeitos da adição de leveduras seca (LS), levedura hidrolisada (LH) e MOS da levedura Saccharomyces cerevisiae na dieta de leitões desmamados com 25 a 70 dias de idade foram avaliados por Sant'ana et al., (2017). Os autores observaram ao término do experimento que, não houve diferença significativa nos índices produtivos avaliados, consumo alimentar total, ganho de peso e conversão alimentar.

Visto que a inclusão da levedura na dieta de suínos se torna benéfica muitas das vezes, Oliveira, (2012), em seu trabalho, objetivou então avaliar a inclusão da LH e LS na dieta de leitões recém desmamados, afim de se avaliar os índices produtivos, ganho de peso, conversão alimentar e consumo de ração. Os animais foram divididos em dois experimentos, sendo o experimento 1 (25 aos 49 dias) e experimento 2 (50 a 72 dia, havendo desta maneira 3 tratamentos no experimento 1 (0\%, $0,02 \%$ e $0,01 \%)$ de $\mathrm{LH}$ e no experimento 2 ( $0 \%, 0,005 \%$ LH e 0,025\% LS). Ao término dos experimentos, observou-se que não houve diferença estatística entre os tratamentos quando comparados os índices produtivos, deste modo não havendo mudanças significativas no desempenho produtivo dos leitões e isso se deve ao fato das baixas dosagem da inclusão das leveduras.

Pereira et al., (2012), por sua vez, ao avaliaram a inclusão do extrato de levedura em substituição do plasma sanguíneo em dietas para leitões dos 21 aos 35 dias, organizados em 5 tratamentos, sendo eles, $4 \%$ de plasma sanguíneo e $2 \%$ de plasma sanguíneo com $0 \%, 1 \%, 2 \%$ e 3\% de extrato de levedura, os autores observaram que a inclusão do extrato de levedura resultou em uma resposta quadrática no consumo diário de ração e peso final, neste caso havendo um ponto de quebra de produtividade na inclusão de até $1,91 \%$.

Já Trckova et al., (2013), ao avaliaram os efeitos da inclusão da levedura S. cerevisiae na resposta imune, crescimento e desempenho de leitões no pós-desmame, observaram que, os animais alimentados com a dieta experimental (5g de levedura $/ \mathrm{kg}$ do animal) apresentaram escore de diarreia mais baixo, a adição da levedura aumentou significativamente os níveis de IgA no soro dos leitões além de contribuir significativamente para o crescimento e desempenho dos leitões.

O desempenho e viabilidade econômica da inclusão de levedura mista (cerveja + cana-de-açúcar - LEV40) em cinco níveis $(0,5,10,15$ e $20 \%)$ na forma farelada na dieta de leitões na fase inicial foi objeto de estudos de Poveda Parra et al., (2013). Os pesquisadores observaram que, a inclusão de até $20 \%$ de LEV40 não afeta o desempenho dos animais, quanto a viabilidade econômica fica a depender da relação de preço entre os ingredientes.

Em estudo conduzido por Molist et al., (2014), foi avaliado a inclusão de levedura hidrolisada na dieta de leitões recém desmamados, no experimento havia uma dieta controle (basal) e uma dieta experimental contendo $2 \mathrm{~g}$ de levedura hidrolisada/kg da ração. Ao término do experimento, foi observado uma melhora no índice de consumo de ração e melhora na conversão alimentar dos animais que consumiram a dieta experimental. 
Missotten et al., (2015), avaliaram o fornecimento de uma dieta com alimentos líquidos fermentados para suínos, onde contém bactérias do ácido lático e leveduras em mistura com água visando reduzir o pH estomacal, em busca da diminuição de organismos patogênicos, ou seja, impedindo a proliferação destes. Deste modo, evidenciando a importância da levedura na dieta de suínos, pois reforça o estomago que atua como a primeira linha de defesa contra infecções patogênicas.

Em estudo realizado por Yang et al., (2016), os autores buscaram avaliar o efeito da utilização de levedura hidrolisada e extrato de levedura sobre o desempenho, fisiologia intestinal e saúde de leitões recém desmamados. Foi utilizado 90 leitões desmamados aos 21 dias de idade submetidos a três tratamentos, dieta controle (basal), dieta contendo $1,2 \mathrm{~g} / \mathrm{kg}$ de levedura e dieta contendo $20 \mathrm{mg} / \mathrm{kg}$ de colistina. Ao término do experimento não se observou diferença significativa na ingestão média diária de ração, ganho médio diário de peso ou melhora na conversão alimentar nos devidos tratamentos.

Kiros et al., (2018), avaliando o efeito de leveduras vivas, Saccharomyces cerevisiae sobre o desempenho e composição da microbiota intestinal de 128 leitões desmamados submetidos a dietas sem e com leveduras, observaram que as utilizações das mesmas não apresentaram resultados significativos para as variáveis, consumo médio diário de ração, ganho médio diário de peso e conversão alimentar.

O crescimento, desempenho e digestibilidade de nutrientes em 150 leitões mestiços (Landrace $\times$ Yorkshire $\times$ Duroc) recém desmamados, com peso inicial de 6,89 $\pm 0,46 \mathrm{~kg}$ (28 dias de idade), submetidos a três tratamentos experimentais ( $\mathrm{T}$ ), sendo eles, T1 controle (basal), T2 0,1\% de extrato de levedura e T3 0,2\% de extrato de levedura, foi tema de pesquisa de Shi \& Kim (2019). Na sexta semana de experimento houve aumento linear $(\mathrm{P}<0,050)$ no ganho de peso médio diário e aumento na digestibilidade aparente de nutrientes da matéria seca dos animais alimentados com níveis crescentes de extrato de levedura, além de melhora no peso corporal e conversão alimentar dos animais.

Visando avaliar os efeitos da levedura Candida utilis (CU) (coproduto de madeira utilizado como fonte de açúcar) em substituição das principais fontes de proteínas, a fim de se analisar o efeito desta sobre o desempenho e função digestiva de 48 leitões desmamados com peso inicial em 11,06 \pm 0,84 kg Cruz et al., (2019) desenvolveram um estudo. Os animais foram alimentados com 4 dietas distintas, sendo elas, controle contendo farinha de soja, dieta contendo farinha de peixe, farinha de colza, dieta contendo proteína de batata ou uma das três dietas experimentais contendo respectivamente 10,20 ou $40 \%$ de proteína bruta de levedura (CU10, CU20 e CU40 respectivamente). A adição da levedura não afetou o crescimento tão pouco o desempenho dos animais em comparação a dieta controle, evidenciando que a inclusão da levedura em substituição das principais fontes de proteína não foi significativa.

Upadhaya et al., (2019), com intuito de avaliar os benefícios da inclusão de leveduras (Saccharomyces cerevisiae) via dietética para leitões desmamados (160 leitões, peso inicial de $7.21 \pm 1.05 \mathrm{~kg}$ ), expostos a ambientes de baixas condições sanitárias, submetidos a dois tipos de dietas/tratamentos, puderam observar que, os animais que tiveram acesso a dieta contendo levedura obtiveram aumento no peso corporal e diferença no ganho de peso diário $(\mathrm{P}<0,05)$ em comparação com o grupo controle. Além disso, a digestibilidade total de matéria foi alterada significativamente $(\mathrm{P}<0,05)$, havendo consequentemente melhora no desempenho dos animais.

\subsection{Uso de Leveduras na Dieta de Suínos na Fase de Crescimento e Terminação}

Nas fases finais de produção de suínos é onde ocorre a maior modificação na carcaça dos animais, devido ao grande aumento e intensificação do rebanho no país, a necessidade de uso de aditivos como a levedura, torna-se fundamental nas fases finais de produção garantindo que haja uma melhor saúde intestinal dos animais e consequentemente um melhor desempenho (Fereira et al., 2019; Fu et al., 2019; Valente Junior et al., 2019).

Cinco níveis de inclusão de levedura nas dietas $(0,5,10,15$ e 20\%) de suínos em crescimento, promoveram uma redução linear $(\mathrm{P}<0,01)$, no ganho de peso dos animais com o aumento dos níveis de inclusão da levedura, assim como não foi 
observada diferença significativa $(\mathrm{P}>0,01)$, na conversão alimentar, mas resultados opostos no consumo de ração diário foram encontrados (Poveda-Parra et al., 2013).

Li e Kim, (2014), avaliando suínos na fase de crescimento $(24,91 \pm 1,06 \mathrm{~kg})$, extrato de parede celular da levedura Saccharomyces cerevisiae, com adição nas dietas suplementadas de 0\%, 0,05\% ou 0,10\%, e observaram que houve melhora no ganho de peso e conversão alimentar dos animais

A ação das leveduras, pode ser influenciada pelo ambiente e a carga de patógenos presentes que os animais estão submetidos (Shen et al., 2017) que pode explicar a variedade de resultados com efeitos benéficos observados por Kiros et al., (2019), Shen et al., (2017), em contrapartida autores como Luna et al., (2015), Robles et al., (2013) que não observaram eficiência na utilização das leveduras na dieta de suínos.

Mendes Palácios et al., (2017) avaliando o uso de leveduras, associadas a prebióticos Lactobacillus spp., Bacillus spp., em diferentes fases sendo dos 70 aos 100, 100 aos 125, 125 aos 150 dias de idade, foi observado que na fase de terminação do experimento (125 aos 150 dias) não houve diferença significativa $(\mathrm{P}<0,05)$ no consumo de ração, mas os animais apresentaram resultados significativos $(\mathrm{P}<0,05)$ na conversão alimentar e ganho de peso das dietas que continham leveduras, resultados diferentes observados no presente estudo.

Cruz et al., (2019) observaram que não há prejuízos na conversão alimentar dos animais quando há o uso de leveduras na dieta, fazendo com que a mesma não aumente na fase de crescimento dos animais. Hardy, (2002), cita que pode haver uma melhora no aproveitamento dos nutrientes das dietas quando há o uso de leveduras na dieta de suínos, pois as mesmas atuam disponibilizando os nutrientes para melhor absorção.

Os resultados controversos na literatura podem estar associados com a variabilidade de produtos em disposição, sendo, a cultura de levedura, o extrato de levedura, a levedura hidrolisada, pois o processamento das mesmas, podem influenciar no modo de ação destas (Fu et al., 2019).

\section{Considerações Finais}

Os efeitos benéficos do uso das leveduras nas dietas de suínos são demonstrados em diversos estudos, possuindo ação probiótica ou prebiótica, dependendo da sua composição e o processamento a qual a mesma foi submetida, além da variabilidade de espécies e microrganismos encontrados para utilização das leveduras em dietas de suínos.

A diversidade de resultados encontrados na literatura, demonstram que há necessidade de mais estudos utilizando a levedura como aditivo na ração de suínos em diversas fases, buscando resultados que impactam positivamente no desempenho e na saúde intestinal.

\section{Referências}

Almeida, L. M., Panisson, J. C., Bonardi, A. J. K., Massuquetto, A., Maiorka, A., \& Scandolera, A. J. (2017). Dietary inclusion of symbiotic in post weaning piglets with nutritional challenge. Archives of Veterinary Science. 22, 3. 57-65. 10.5380/avs.v22i3.52265.

Araújo, W. A. A., Brustolini, P. C., Ferreira, A. S., Silva, F. C. O., Abreu, M. L. T., \& Lanna, E. A. (2011). Comportamento de leitões em função da idade de desmame. Revista Brasileira de Saúde e Produção Animal, 12, 3. 758-769. Recuperado de rbspa/article/view/40562/22535.

Assis, S. D., Luna, U. V., Junior, J. G. C., Correa, G. S. S., Correa, A.B., \& Brusamarelo, E. (2014). Desempenho e características morfo- intestinais de leitoas desmamadas alimentadas com dietas contendo associações de mananoligossacarídeo. Archives of Veterinary Science. v.19, n.4, p.33-41, 2014. 10.5380/avs. v19i4.35581

Barba-Vidal, E., Martin Ouré, S. M., \& Castilejos, L. (2019). Practical aspects of the use of probiotics in pig production: A review. Livestock Science. 223. 8496. 10.1016/j.livsci.2019.02.017.

Berto, P. N. (2017). Suplementação dietética de levedura hidrolisadas e seu efeito no desempenho, na microbiota intestinal e resposta imune dos leitões desmamados. Dissertação. Programa de Pós-graduação em Nutrição e produção animal da Faculdade de veterinária e zootecnia da Universidade de São Paulo. https://bdpi.usp.br/item/002884180. 
Bezerra, W. G. A., Horn, R. H., Silva, I. N. G., Teixeira, R. S. C., Lopes, E. S., Albuquerque, Á. H., \& Cardoso, W. C. (2017). Antibióticos no setor avícola: uma revisão sobre a resistência microbiana. Archivos de Zootecnia. 66 301-307. 10.21071/az.v66i254.2335.

Brito, J. M., Ferreira, A. H. C., Junior, H. A. S., Araripe, M. N. B. A., Lopes, J. B., Duarte, A. R., Cardoso, E. S., \& Rodrigues, V. L. (2013). Probióticos, prebióticos e simbióticos na alimentação de não-ruminantes - Revisão. Revista eletrônica Nutritime. 10. 04.2525 - 2545.

Campbell, J. M., Crenshaw, J. D., \& Polo, J. (2013). The biological stress of early weaned piglets. Journal of Animal Science and Biotechnology, 4. 19-24. $10.1186 / 2049-1891-4-19$.

Chamone, J. M. A., Melo, M. T. P., Arouca, C. L. C., Barbosa, M. M., Souza, F. A. E., \& Santos, D. (2010). Fisiologia digestiva de leitões. Revista Eletrônica Nutritime. 07. 1353-136.

Cruz, A., Hakenasen, I. M., Skugor, A., Mydland, L. T., Akesson, C. P., Hellestveit, S. S., Sorby, R., Press, C. M. C. L., \& Overland, M. (2019). Candida utilis yeast as a protein source for weaned piglets: Effects on growth performance and digestive function. Livestock Science. 226. 31-39, 2019. 10.1016/j.livsci.2019.06.003.

Dong, L., Li, H. M., Wang, S. N., Wang, T. L. Yu, L. H., \& Wang, H. R. (2021). Meishan Neonatal Piglets Tend to Have Higher Intestinal Barrier Function Than Crossbred Neonatal Piglets. animal. 15. 10.1016/j.animal.2020.100037.

Feitosa, T. J. O., Silva, C. E., Souza, R. G., Lima, C. D. S., Gurgel, A. C., Oliveira, L. L. G., Nóbrega, J. G. S., Carvalho Júnior, J. E. M., Melo, F.O., Santos, W. B. M. Feitoza, T. O., Costa, T. F., Brandão, P. A., \& Minafra, C. S. (2020). Intestinal microbiota of poultry: bibliographic review. Research, Society and Development, 9. 5.10.33448/rsd-v9i5.2779.

Ferreira, D. N. M., Junior Dutra, W. M., Palhares, L. O., \& Coelho, A. H. S. C. (2019). Desempenho e características de carcaça de suínos em crescimento alimentados com torta de algodão e complexo enzimático. Arquivo Brasileiro de Medicina Veterinaria e Zootecnia. 71, 1616-1622. 10.1590/1678-416210305.

Fu, R., Chen, D., Tian, G., Zheng, P., Mao, X., Yu, J., He, J., Huang, Z., Luo, Y., \& Yu, Bing. (2019). Dietary supplementation of Bacillus coagulansor yeast hydrolysates on growth performance, antioxidant activity, cytokines and intestinal microflora of growing-finishing pigs. Journal Animal Nutrition. 5, 366-372. 10.1016/j.aninu.2019.06.003.

Garcia, R., Dogi, C. A., Poloni, V. L., Fochesato, A. S., Leblanc, A. M., Cossalter, A. M., Payros, D., Oswald, I. P. \& Cavaglieri, L. R. (2019). Beneficial effects of Saccharomyces cerevisiae RC016 in weaned piglets: in vivo and ex vivo analysis.Beneficial Microbes. 8. 10. 33-42. 10.3920/BM2018.0023.

Gazoni, F. L. (2015). Prevalência de Coccidiose e correlação com a saúde intestinal de frangos de corte em agroindústrias Brasileiras entre os anos de 2012 a 2014. Dissertação de Mestrado. Universidade Federal de Santa Maria, Centro de Ciências Rurais, Programa de Pós-graduação Medicina Veterinária. repositorio.ufsm.br/bitstream/handle/1/10216/GAZONI.

González-Ortiz, G., Callegari, M. A., Wilcock, P., Melo-Duran, D., Bedford, M. R., Oliveira, H. R. V., \& Silva, C. A. (2020). Dietary xylanase and live yeast supplementation influence intestinal bacterial populations and growth performance of piglets fed a sorghum-based diet. Animal Nutrition. 10.1016/j.aninu.2020.05.005

Halas, V., \& Nochta, I. (2012). Mannanoligosaccharides in nursery pig nutrition and their potential mode of action. Animals. 2, $261-274$. 10.3390/ani2020261.

Hardy, B. (2006). The issue of antibiotic use in the livestock industry: what have we learned? Animal Biotechnology. 13. 129-47. 10.1081/ABIO-120005775.

Karasova, D., Crhanova, M., Babak, V., Jerebek, M., Brzobohaty, L., Matesova, Z., \& Rychilk, I. (2021). Development of Piglet Gut Microbiota at The Time Of Weaning Influences Development Of Postweaning Diarrhea - A Field Study. Research In Veterinary Science. 135. 59-65. 10.1016/J.RVSC.2020.12.022.

Kiros, T. G., Derakhshani, H., Pinloche, E., D'inca, R., Marshall, J., Auclair, E., Khafipour, E., \& Van Kessel, A. (2018). Effect of live yeast Saccharomyces cerevisiae (ActisafSc 47) supplementation on theperformance and hindgutmicrobiota composition of weanling pigs. Scientific reports, 8. 53-64. $10.1038 / \mathrm{s} 41598-018-23373-8$

Kuhn, O. J., Nunes, R.V., Stangarlin, J. R., Rampim, L., Fey, R., Costa, P. B., Costa, N. V., Guimarãs, V. F., \& Zambom, M. A. (2015). Ciências agrárias: tecnologias e perspectivas. 360. Universidade Estadual do Oeste do Paraná. 10.12702/978-85-68205-03-7

Li, P. F., Piao, X. S., Ru, Y. J., Han, X., Xue, L. F., \& Zhang, H. Y. (2012). Effects Of adding essential oil to the diet of weaned pigs on performance nutrient utilization, immune response and intestinal health. Journal Animal Science. 25. 10.5713 / ajas.2012.12292.

Lima, M. D., Lopes, I. M. G., Silva, K. F., Miranda, H. A. F., Almeida, A. C., \& Duarte, E. R. (2020). Use of additivies in diets for piglets in nursing stage: a review. Research, Society and Development, 9, 12, 10.33448/rsd-v9i12.11081.

Liu, Y., Espinosa, C. D., Abelilla, J. J., Casas, G. A., Lagos, L. V., Lee, A. A., Kwon, W. B., Mathai, J. K., Navarro, D. M. D. L., Jaworski, N. W., \& Stein, H. H. (2018). Non-antibiotic feed additives in diets for pigs: A review. Animal Nutrition. 4. 113- 125. 10.1016/j.aninu.2018.01.007.

Lopes, I. M. G., Souza, J. P. P., Lima, M. D., Silva, K. F., \& Santos, M. C. (2021). Influence of the reproductive cycle on the zootechnical indexes in hyperproliferous swine matrices. Research, Society and Development, 10. 2. 10.33448/rsd-v10i2.12367.

López-Gálvez, G., López-Alonso, M., Pechova, A., Mayo, B., Dierick, N., \& Gropp, J. (2020). Alternatives to antibiotics and trace elements (copper and zinc) to improve gut health and zootechnical parameters in piglets: A review. Animal Feed Science and Technology. 10.1016/j.anfeedsci.2020.114727

Lu, X., Zhang, M., Zhao, L., Ge, K., Wang, Z., Jun, L., \& Ren, F. (2018) Growth Performance and Post-Weaning Diarrhea in Piglets Fed a Diet Supplemented with Probiotic Complexes. Journal of Microbiology and Biotechnology. 1791-1799. 10.4014/jmb.1807.07026.

Luna, U. V., Caramori Junior, J. C., Corrêa, G. S. S., Kiefer, C., Souza, M. A., Vieites, F. M., Cruz, R. A. S., \& Assis, S. D. (2015) Mananoligossacarídeo e Bglucano em dietas de leitões desmamados. Arquivo Brasileiro de Medicina Veterinária e Zootecnia. 67. 2. 591-599, 10.1590/1678-7146. 
Malheiros, F. M. (2019). Quantificação bioecônomica do impacto do bem-estar no desmame e final de creche de suínos. Dissertação (Mestrado em agronegócios), Universidade Federal de Santa Maria (UFSM, RS). https://repositorio.ufsm.br/handle/1/15286.

Missotten, J. A. M., Michiels, J., Degroote, J., \& De Smet, S. (2015). Fermented liquid feed for pigs: an ancient technique for the future. Journal of Animal Science and Biotechnology. 6. 10.1186/2049-1891-6-4.

Molist, F., Eerden, E., Parmentier, H. K., \& Vuorenmaa, J. (2014). Effects of inclusion of hydrolyzed yeast on the immune response and performance of piglets after weaning. Animal Feed Science and Technology. 195, 136-141. 10.1016/j.anifeedsci.2014.04.020.

Oliveira, M. T. (2012). Inclusão de levedura hidrolisada e levedura seca na dieta de leitões recém-desmamados. 65p, Dissertação (Mestrado em Medicina Veterinária) - Universidade Federal de Uberlândia, 2012. https://repositorio.ufu.br/handle/123456789/13037.

Patil, A, K., Kumar, S., Verma, A. K., \& Baghel, R. P. S. (2015). Probiotics as Feed Additives in Weaned Pigs: A Review. Livestock Research International. 3. 31-39. 10.3923/javaa.2011.2127.2134. Pereira, A. S., Shitsuka, D. M., Parreira, F. J., \& Shitsuka, R. (2018). Metodologia da pesquisa científica. UFSM. http://repositorio.ufsm.br/handle/1/15824.

Pereira, C. M. C., Donzele, J. L., Silva, F. C. O., Oliveira, R. F. M., Kiefer, C., Ferreira, A. S., Hannas, M. I., \& Brustolini, P. C. (2012). Yeast extract with blood plasma in diets for piglets from 21 to 35 days of age. Revista Brasileira de Zootecnia. v.41. p.1676-1682. 10.1590/S1516-35982012000700017.

Pluske, J. R., Turpin, D. L., \& Kim, J-C. (2018). Gastrointestinal tract (gut) health in the young pig. Animal Nutrition, 187-196, 10.1016/j.aninu.2017.12.004.

Poveda-Parra, A. R., Moreira, I., Furlan, A. C., Carvalho, P. L. O., Peñuela Sierra, L. M., \& Filho, C. C. (2013). Levedura mista (cerveja + cana-de-açúcar) spray-dry na alimentação de leitões na fase inicial. Archivos de zootecnia. 62. 199-209. 10.4321/S0004-05922013000200005.

Robles-Huaynate R. A., Thomaz M. C., Santana A. E., Masson G. C. I. H., Amorim A. B., Silva S. Z., Ruiz U. S., Watanabe P. H., \& Budiño F. E. L. (2013). Efeito da adição de probiótico em dietas de leitões desmamados sobre as características do sistema digestório e do desempenho. Revista Brasileira de Saúde e Produção Animal. 14. 248-258. 10.1590/S1519-99402013000100009.

Rostagno, H. S., \& Pupa, J. M. R. (2018). Fisiologia da digestão e alimentação de leitões. Nutritime Revista Eletrônica.15. 05.

Sant'ana, D. S., Magalhães, M. L., Magalhães, C. F., Antunes, R. C., Oliveira, M. T., Mundim, A. V., \& Freitas, P. F. A. (2017). Efeitos da adição de leveduras (Saccharomyces cerevisiae) na ração de leitões desmamados. Investigação. 16-21. 10.26843/investigação. v16i8.1744.

Santos, L. S., Mascarenhas, A. G., \& Oliveira, H. F. (2016). Fisiologia digestiva e nutrição pós desmame em leitões. Revista Nutritime. 13. 01.

Sessin, A. P. (2018). Óleos funcionais como promotores de crescimento na dieta de leitões desmamados. Trabalho de Conclusão de Curso. Graduação em Zootecnia, Universidade Federal de Santa Catarina, Florianopolis. repositorio.ufsc.br/handle/123456789/194849.

Shen, Y. B., Fellner, V., Yoon, I., \& Kim, S. W. (2017). Effects of dietary supplementation of Saccharomyces cerevisiae fermentation product to sows and their offspring on growth and meat quality. Translational Animal Science .45-53. 10.2527/tas2016.0005.

Shi, H., \& Kim, H. (2019). Dietary yeast extract complex supplementation increases growth performance and nutrient digestibility of weaning pigs. Livestock Science, 230. 10.1016/j.livsci.2019.103850.

Shurson, G. C. (2018). Yeast and yeast derivatives in feed additives and ingredients: Sources, characteristics, animal responses, and quantification methods. Animal Feed Science and Technology. 235.60-76. 10.1016/j.anifeedsci.2017.11.010.

Silva, F. B., Arrais, B. R., Ferreira, M. R. A., Sobrinho, I. S. J., Dias, M., \& Moreira, C. N. (2020). Microbiological quality of seasoned chicken cuts using Escherichia coli and Salmonella spp. as quality indicators. Research, Society and Development. 9. 11. 10.33448/rsd-v9i11.10013.

Silva, G. A., Rorig, A., Schimidt, J. M., \& Guirro, E. C. B. P. (2014). Impacto do desmame no comportamento e bem-estar de leitões: revisão de literatura. Veterinária em Foco, 12, 1. http://www.periodicos.ulbra.br/index.php/veterinaria/article/view/1507.

Silva, S. Z., Thomaz, M. C., Watanabe, P. H., Robles-Huaynate R. A., Ruiz, U. S., Pascoal, L. A., Santos V. M., \& Masson, G. C. I. H. (2012) Mananoligossacarídeo em dietas para leitões desmamados. Brazilian Journal of Veterinary Research Animal Science. 49(2).102-110. 10.11606/issn.23183659.v49i2p102-110.

Silva, S. Z., Thomaz, M. C., Watanabe, P. H., Robles-Huaynate R. A., Ruiz, U. S., Pascoal, L. A., Santos V. M., \& Masson, G. C. I. H. (2012). Mananoligossacarídeo em dietas para leitões desmamados. Brazilian Journal of Veterinary Research Animal Science. 49(2). 102-110.2012. 10.11606/issn.2318-3659.v49i2p102-110.

Souza, C. S., Vieites, F. M., Justino, L. R., Lima, M. F., Chaves, A. S., Cardoso, V.S., Sousa, F. D. R., Costa, T. F., Minafra, C. \& Lima, C. A. R. (2020). Importance of intestinal health in broilers. Research, Society and Development, 9. 3. 10.33448/rsd-v9i3.2475.

Trckova, M., Faldyna, M., Alexa, Z., Sramkova-Zajacova, E., Gopfert, D., Kumprechtova, E., \& Auclair D. I. (2013). The effects of live yeast Saccharomyces cerevisiae on post-weaning diarrehea, imune response and growth performance in weaned piglets. Journal of Animal Science .92 767-74 10.2527/jas.20136793.

Upadhaya, S. D., Laguna, F. B., Bertaud, B., \& Kim, I. (2019). Multi-strain yeast fraction product supplementation can alleviate weaning stress and improve performance and health of piglets raised under low sanitary conditions. Journal Science Food Agriculture, 6076-6083. 10.1002/jsfa.9885.

Valente Junior, D. T., Soares, M. H., Barbosa, L. M. R., Rodrigues, G. A., Reis, M. D. G., Gomes, M. S., \& Saraiva, A. (2019). Suplementação de betaína na dieta de Suínos em terminação: Revisão. PUBVET. 13, 3,1-12. 10.31533/pubvet.v13n3a288.1-12.

Vargas, L. (2014). Efeitos da utilização de MOS e ácidos orgânicos no desempenho de leitões. Trabalho de Conclusão de Curso. Graduação em Zootecnia, Universidade Tecnológica Federal do Paraná, s Vizinhos, repositorio.roca.utfpr.edu.br/jspui/handle/1/8469. 
Research, Society and Development, v. 10, n. 3, e24810313271, 2021

(CC BY 4.0) | ISSN 2525-3409 | DOI: http://dx.doi.org/10.33448/rsd-v10i3.13271

Vicari Junior, D., Zimmer, F., Gugel, J., Campigotto, G., Tavernari, F. C., Boiago, M. M., Silva, A. S. \& Paiano, D. (2020). Supplementation with spray-dried porcine plasma in piglets at birth: effects on protein metabolism and performance. Research, Society and Development. $9,8.10 .33448 / \mathrm{rsd}-\mathrm{v} 9 \mathrm{i} 8.5552$

Vohra, A., Syal, P., \& Madan, A. (2016). Probiotic yeasts in livestock sector. Animal Feed Science and Technology. 219. 31-47. 10.1016/j.anifeedsci.2016.05.019.

Wang, H., Li, S., Xu, S., \& Feng, J. (2020). Betaine improves growth performance by increasing digestive enzymes activities, and enhancing intestinal structure of weaned piglets. Animal Feed Science and Technology. 10.1016/j.anifeedsci.2020.114545.

Wang, L., Tan, X., Wang, H., Wang, Q., Huang, P., Li, Y., Li, J. Huang, J., Yang, H., \& Yin, Y (2020). Efects of varying dietary folic acid during weaning stress of piglets. Animal Nutrition. 10.1016/j.aninu.2020.12.002.

Xiong, X., Yang, H., Li, B., Liu, G., Huang, R., Li, F., Liao, P., Zhang, Y., Nyachoti, C. M., \& Deng, D. (2015). Dietary supplementation with yeast product improves intestinal function, and serum and ileal amino acid contents in weaned piglets. Livestock Science, 171. 20-27. 10.1016/j.livsci.2014.10.012.

Xu, Y. T., Liu, L., Long, S. F., Pan, L., \& Pião, X. S. (2017). Effect of organic acids and essential oils on performance, intestinal health and digestive enzyme activities of weaned pigs. Animal Feed Science and Technology, 10.1016/j.anifeedsci.2017.10.012.

Yang, H.S., Wu, F., Long, L. N., Li, T. J., Xiong, X., Liao, P., Liu, H. N., \& Yin, Y. L. (2017). Effects of yeast products on the intestinal morphology, barrier function, cytokine expression, and antioxidant system of weaned piglets. Journal of Zhejiang University-Science B (Biomedicine \& Biotechnology). 17. 752762. $10.1631 /$ jzus.B1500192.

Zeng, Z. K., Xu, X., Zhang, Q., Li, P., Zhao, P. F., Li, Q.Y., Liu, J. D., \& Piao, X. S. (2014). Effects of essential oil supplementation of a low-energy diet on performance, intestinal morphology and microflora, immune properties and antioxidant activities in weaned pigs. Journal Animal Science. 86, 279-285. 10.1111/asj.12277.

Zeng, Z. K., Zhang, S., Wang, H. L., \& Piao, X. S. (2015). Essential oil and aromatic plants as feed additives in non-ruminant nutrition: a review. Journal Animal Science. Biotechnol.6-7. 10.1186/s40104-015-0004-5.

Zhang, J. Y., Park, J. W., \& Kim, I, O. (2019). Effect of supplementation with brewer's yeast hydrolysate on growth performance, nutrients digestibility, blood profiles and meat quality in growing to finishing pigs. Journal of Animal Sciences. 32 .10. 10.5713/ajas.18.0837.

Zhang, Q., Li, J., Cao, M., Li, Y., Zhuo, Y., Fang, Z., \& Wu, D. (2020). Dietary supplementation of Bacillus subtilis PB6 improves sow reproductive performance and reduces piglet birth intervals. Animal Nutrition. 10.1016/j.aninu.2020.04.002. 